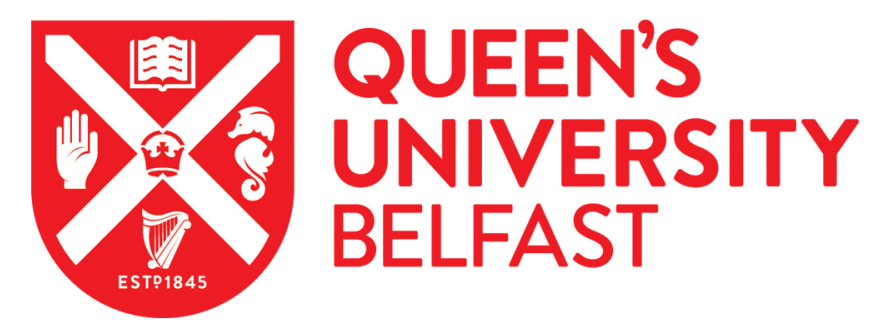

\title{
Association of ambient air pollution with age-related macular degeneration and retinal thickness in UK Biobank
}

Chua, S. Y. L., Warwick, A., Peto, T., Balaskas, K., Moore, A. T., Reisman, C. A., Desai, P., Lotery, A. J., Dhillon, B., Khaw, P. T., Owen, C. G., Khawaja, A. P., Foster, P. J., \& Patel, P. J. (2021). Association of ambient air pollution with age-related macular degeneration and retinal thickness in UK Biobank. British Journal of Ophthalmology. https://doi.org/10.1136/bjophthalmol-2020-316218

Published in:

British Journal of Ophthalmology

Document Version:

Peer reviewed version

Queen's University Belfast - Research Portal:

Link to publication record in Queen's University Belfast Research Portal

Publisher rights

Copyright $2021 \mathrm{BMJ}$

This manuscript is distributed under a Creative Commons Attribution-NonCommercial-NoDerivs License

(https://creativecommons.org/licenses/by-nc-nd/4.0/), which permits distribution and reproduction for non-commercial purposes, provided the author and source are cited.

\section{General rights}

Copyright for the publications made accessible via the Queen's University Belfast Research Portal is retained by the author(s) and / or other copyright owners and it is a condition of accessing these publications that users recognise and abide by the legal requirements associated with these rights.

Take down policy

The Research Portal is Queen's institutional repository that provides access to Queen's research output. Every effort has been made to ensure that content in the Research Portal does not infringe any person's rights, or applicable UK laws. If you discover content in the Research Portal that you believe breaches copyright or violates any law, please contact openaccess@qub.ac.uk. 


\section{Association of ambient air pollution with age-related macular degeneration and retinal thickness in UK Biobank}

Sharon YL Chua PhD (1,2); Alasdair Warwick (3); Tunde Peto (4);Konstantinos Balaskas (1,5) Anthony T Moore FRCOphth $(2,6)$; Charles Reisman (7); Parul Desai PhD FRCOphth (8); Andrew J Lotery (9); Baljean Dhillon FRCS(Ed) FRCOphth(10,11); Peng T Khaw PhD FMedSci (1,2); Christopher Owens (12); Anthony P Khawaja $(1,2,8)$; Paul J Foster* PhD FRCS(Ed) $(1,2,8)$; Praveen J Patel ${ }^{*}$ MD FRCOphth $(1,8)$; on behalf of The UK Biobank Eye and Vision Consortium

\section{Author affiliations:}

1. NIHR Biomedical Research Centre at Moorfields Eye Hospital NHS Foundation Trust \& UCL Institute of Ophthalmology, London, UK

2. UCL Institute of Ophthalmology, London, UK

3. UCL Institute of Cardiovascular Science, UK

4. School of Medicine, Dentistry and Biomedical Sciences, Queens University Belfast, Belfast, UK.

5. School of Biological Sciences, University of Manchester, Manchester, UK

6. Ophthalmology Department, University of California, San Francisco, USA

7. Topcon Healthcare Solutions Research \& Development, Oakland, New Jersey, USA

8. Moorfields Eye Hospital, London, UK

9. Clinical and Experimental Sciences, Faculty of Medicine, University of Southampton, Southampton, UK

10. Centre for Clinical Brain Sciences, School of Clinical Sciences, University of Edinburgh, Edinburgh, UK

11. NHS Lothian Princess Alexandra Eye Pavilion, Edinburgh, UK

12. Population Health Research Institute, St. George's, University of London, London, UK

* Joint senior authors taking joint credit and responsibility

Correspondence to: Paul Foster

Address: UCL Institute of Ophthalmology, 11-43 Bath Street, London, EC1V 9EL

Email: p.foster@ucl.ac.uk

Telephone: 07971663189

Word count: 3,779 


\section{SYNOPSIS}

Age-related macular degeneration (AMD) is the leading cause of vison loss among the elderly in high income countries. Increased exposure to air pollution may be associated with AMD and differences in retinal layer thickness. 


\section{$1 \quad$ ABSTRACT}

2 Aim: To examine the associations of air pollution with both self-reported age related macular degeneration (AMD), and in vivo measures of retinal sub-layer thicknesses.

4 Methods: We included 115,954 UK Biobank participants aged 40 to 69 years old in

5 this cross-sectional study. Ambient air pollution measures included particulate matter,

6 nitrogen dioxide $\left(\mathrm{NO}_{2}\right)$ and nitrogen oxides $(\mathrm{NO})$. Participants with self-reported

7 ocular conditions, high refractive error (<-6 or $>+6$ diopters) and poor spectral-domain

8 optical coherence tomography (SD-OCT) image were excluded. Self-reported AMD

9 was used to identify overt disease. Spectral-domain optical coherence tomography 10 (SD-OCT) imaging derived photoreceptor sub-layer thickness and retinal pigment epithelium (RPE) layer thickness were used as structural biomarkers of AMD for 52,602 participants. We examined the associations of ambient air pollution with selfreported AMD and both photoreceptor sub-layers and retinal pigment epithelium (RPE) layer thicknesses.

Results: After adjusting for covariates, people who were exposed to higher fine ambient particulate matter with an aerodynamic diameter $<2.5 \mu m\left(\mathrm{PM}_{2.5}\right)$ (per interquartile range $[I Q R]$ increase) had higher odds of self-reported $A M D(O R=1.08$, $p=0.036)$, thinner photoreceptor synaptic region $\left(\beta=-0.16 \mu \mathrm{m}, \mathrm{p}=2.0 \times 10^{-5}\right)$, thicker photoreceptor inner segment layer $(\beta=0.04 \mu \mathrm{m}, \mathrm{p}=0.001)$ and thinner RPE $(\beta=-$ $0.13 \mu \mathrm{m}, \mathrm{p}=0.002)$. Higher levels of $\mathrm{PM}_{2.5}$ absorbance and nitrogen dioxide $\left(\mathrm{NO}_{2}\right)$ were associated with thicker photoreceptor inner and outer segment layers, and a thinner RPE layer. Higher levels of $\mathrm{PM}_{10}$ (PM with an aerodynamic diameter $<10 \mu \mathrm{m}$ ) was associated with thicker photoreceptor outer segment and thinner RPE, while higher exposure to $\mathrm{NO}_{x}$ was associated with thinner photoreceptor synaptic region. 
25 Conclusion: Greater exposure to $\mathrm{PM}_{2.5}$ was associated with self-reported AMD, while

$26 \mathrm{PM}_{2.5}, \mathrm{PM}_{2.5}$ absorbance, $\mathrm{PM}_{10}, \mathrm{NO}_{2}$ and $\mathrm{NO}_{x}$ were all associated with differences in

27 retinal layer thickness. 


\section{INTRODUCTION}

Age-related macular degeneration (AMD) is the leading cause of irreversible blindness in adults 50 years and above in high income countries. ${ }^{1}$ Dry AMD is characterized by progressive dysfunction of the retinal pigment epithelium (RPE), photoreceptor loss and retinal degeneration. ${ }^{2}$ By 2020, the global projected number of people with AMD is approximately 200 million, increasing to nearly 300 million by $2040 .^{3}$ Well-known risk factors include older age, smoking and genetic factors. ${ }^{1}$ A constellation of adverse factors (both risk genotypes, smoking and body mass index $[\mathrm{BMI}] \geq 25$ ) together increases the risk 19 -fold. ${ }^{4}$ As smoking tobacco is a risk factor, it is plausible that ambient air pollution may also be a modifiable risk factor.

Air pollution is one of the world's most important environmental health risks. It is associated with increased mortality and morbidity. ${ }^{5}$ Exposure to air pollution is associated with pulmonary and cardiovascular disease ${ }^{6}$ and eye diseases including glaucoma ${ }^{7}$ and AMD. ${ }^{8}$ The mechanisms of air-pollution-induced health effects may likely involve oxidative stress and inflammation. ${ }^{9}$ The retina is one of the highest oxygen-consuming tissues in the human body and resides in an environment that is primed for the generation of reactive oxygen species (ROS) and resultant oxidative damage. ${ }^{10}$ Oxidative damage increases with age, resulting in retinal dysfunction and cell loss. Rapid, non-invasive optical coherence tomography (OCT) imaging of the retina is now commonly used by community opticians and hospital eye clinics and to assess retinal structural changes associated with $A M D$, and to guide its management. ${ }^{11}$ 
52 If air pollution has an adverse effect on AMD risk, this may offer a new range of

53 interventions for controlling this important condition. We examined data from UK

54 Biobank, a large community-based cohort study. The aim of our study was to evaluate 55 the relationship between ambient air pollution, AMD status and OCT imaging derived 56 structural features of the disease: photoreceptor sub-layer and RPE layer thickness.

METHODS

\section{Study population}

UK Biobank (UKBB) is a very large community-based cohort of 502,656 UK residents registered with the National Health Service (NHS) and aged 40-69 years at enrolment.

62 Baseline examinations were carried out between 2006-2010 at 22 study assessment

63 centres. The North West Multi-centre Research Ethics Committee approved the study in accordance with the principles of the Declaration of Helsinki. The overall study protocol (http://www.ukbiobank.ac.uk/resources/) and protocols for individual tests (http://biobank.ctsu.ox.ac.uk/crystal/docs.cgi) are available online. Participants answered a wide-ranging touch-screen questionnaire covering demographic, socioeconomic, lifestyle, systemic and ocular diseases information. Definition of hypertension was based on self-reported. Physical measures included height and weight. Body mass index (BMI) was defined as weight divided by height squared.

\section{Ocular assessment}

Ocular assessment was introduced as an enhancement in 2009 for six assessment 
using a logarithm of the minimum angle of resolution (LogMAR) chart (Precision Vision, LaSalle, Illinois, USA) on a computer screen under standard illumination. ${ }^{12,13}$ Refractive error was measured using an autorefractor (Tomey RC 5000, Nagoya, Japan). ${ }^{14}$ High resolution OCT imaging was performed using the Topcon 3D OCT 1000 Mk2 (Topcon Inc, Oakland, NJ, USA) in a dark room, without pupillary dilation using the 3D macular volume scan (scan settings: 512 horizontal A scans per B scan; 128 B scans in a $6 \times 6 \mathrm{~mm}$ raster pattern). The Topcon Advanced Boundary Segmentation (TABS) Algorithm (Version 1.6.1.1) ${ }^{15}$ was used to detect retinal layer boundaries and measure the thickness of the $\mathrm{RPE}^{16}$ and photoreceptor sub-layers. (Supplementary Figure 1). The TABS segmentation algorithm has been validated previously showing a high degree of precision and reproducibility compared to manual segmentation methods. ${ }^{15}$ Strict quality control was implemented to exclude images of poor quality as described in detail previously. ${ }^{17}$ OCT scans with image quality score (signal strength) $<45$ were excluded. Several segmentation indicators were calculated to identify poor scan quality or segmentation failures. Participants with the poorest $20 \%$ of images for each of these indicators were also excluded. These indicators included an inner limiting membrane (ILM) indicator, a validity count, and motion indicators. The ILM indicator was a measure of the minimum localized edge strength around the ILM boundary across the entire scan. It is useful for identifying blinks, scans that contain regions of severe signal fading, and segmentation errors. The validity count indicator is used to identify scans with a significant degree of clipping in the OCT scan's z-axis dimension. The motion indicators use both the nerve fibre layer and the full retinal thicknesses, from which Pearson correlations and absolute differences between the thickness data from each set of consecutive B-scans are calculated. The lowest correlation and the highest absolute difference in a scan serve as the resulting 
100 indicator scores and identify blinks, eye motion artifacts, and segmentation failures.

101 The image quality score and the aforementioned indicators usually are highly 102 correlated. ${ }^{18}$

103 Definition of AMD status

104 Definition of AMD status was based on self-reported data. AMD status was determined as those who selected "macular degeneration" from a predefined list of eye disorders

106 to the question "Has a doctor ever told you that you have any of the following problems

107 with your eyes?" We also carried out a validation of self-reported AMD status by 108 carrying out masked grading of the retinal OCT and fundus images for features of AMD based on the Beckman AMD classification on a random subset of age-matched participants. $^{19}$

\section{Estimates of air Pollution}

113 The air pollution estimates were provided by the Small Area Health Statistics Unit

114 (http://www.sahsu.org/) as part of the BioSHaRE-EU Environmental Determinants of Health Project (http://www.bioshare.eu/), and were linked centrally to the assessment data by

UK

Biobank analysts

117 (http://biobank.ctsu.ox.ac.uk/crystal/docs/EnviroExposEst.pdf). Detailed estimates of

118 air pollution parameters have been published. ${ }^{20}$ The annual average concentration of

$119 \mathrm{PM}_{2.5}$ (aerodynamic diameter of less than 2.5 $\mu \mathrm{m}$ ), PMcoarse (aerodynamic diameter 120 between 2.5 and $10 \mu \mathrm{m}, \mathrm{PM}_{10}$ (aerodynamic diameter of less than $10 \mu \mathrm{m}$ ), $\mathrm{PM}_{2.5}$ absorbance (a measurement of the blackness of $\mathrm{PM}_{2.5}$ filter - a proxy for elemental or

122 black carbon), nitrogen dioxide $\left(\mathrm{NO}_{2}\right)$ and nitrogen oxides $(\mathrm{NO})$ were calculated 123 centrally by the UK Biobank using a land use regression model developed by the 
124 European Study of Cohorts for Air Pollution Effects (ESCAPE) project

125 (http://www.escapeproject.eu/) ${ }^{21}$ By using the predictor variables obtained from the

126 Geographic Information System such as traffic, land use, and topography, the land

127 use regression models calculate the spatial variation of annual average air pollution

128 concentration at participants' residential addresses given at baseline visit. $\mathrm{NO}_{2}$ annual

129 concentration data were available for four years (2005, 2006, 2007 and 2010), while

$130 \mathrm{PM}_{10}$ data was available for 2007 and 2010. We averaged the values to obtain the

131 mean estimate. All other particulate matter and nitrogen pollutants had the exposure

132 data for a single year (2010).

\section{Inclusion and exclusion criteria}

135 A uniform set of exclusion criteria was applied in analysis of AMD status, 136 photoreceptor layer and RPE thickness (Figure 1). We excluded data from: (1)

137 participants who withdrew consent; or (2) had self-reported diabetes-related eye 138 disease, eye injury resulting in vision loss or other serious eye conditions; high 139 refractive error (<-6 diopters [D] or $>+6 D$ ) or (3) participants who had poor OCT image 140 scans using TABS software. ${ }^{16,22}$ These participants were excluded because of the 141 well-recognized impact these factors have on retinal layer thickness. ${ }^{23}$

\section{Statistical analysis}

144 The present analysis was based on cross-sectional data collected at one point in time.

145 For this analysis, if both eyes of a patient were eligible for inclusion in the analysis, 146 one eye was randomly selected using STATA software (version 13, StataCorp LP,

147 College Station, TX, USA). We examined the baseline characteristics of participants 
148 included for each specific outcome (self-reported AMD and retinal layers). Descriptive

149 statistics for continuous variables are presented as mean (standard deviation [SD]),

150 whereas categorical variables are presented as number (percentage). We examined

151 the associations of each air pollutant (independent variables) with self-reported AMD

152 (dependent variable) using logistic multivariable regression models, adjusted for age,

153 sex, race, Townsend deprivation index, BMI, smoking status, and refractive error. The

154 associations of air pollutants with photoreceptor sub-layers and RPE thicknesses

155 (dependent variables) were adjusted for the same variables, using linear multivariable

156 regression models. The effect estimates represent the change in self-reported AMD

157 and retinal layers variables per interquartile range (IQR) increment in air pollution.

158 Statistical significance was set at $p<0.05$ for the outcomes self-reported AMD and

159 RPE thickness. When photoreceptor sub-layer thickness was analyzed as an

160 outcome, statistical significance was set at $p<0.002$ after Bonferroni correction as we

161 examined six different types of air pollutants with four distinct photoreceptor related

162 layers. In sensitivity analysis, we examined the associations of air pollutants with

163 visually significant self-reported AMD. Visually significant self-reported AMD was 164 defined as self-reported AMD participants with VA worse than LogMAR 0.3 (equivalent 165 to Snellen 20/40), while non-visually significant self-reported AMD was defined as 166 those with VA of LogMAR 0.3 or better.

\section{Results}

169 Of the 133,964 participants who completed ocular assessment, 24 participants 170 withdrew their consent. Of the 133,940, we excluded 13,329 participants according to 171 the exclusion criteria (Figure 1), leaving data on 120,611 participants. There were 
172 complete data (age, sex, race, Townsend deprivation index, BMI, smoking status,

173 refractive error, self-reported $A M D$ and air pollution measures) for 115,954

174 participants. Of the 115,954 , there was complete OCT imaging data on retinal layers

175 for 68,088 participants. We excluded 15,486 participants according to the exclusion

176 criteria for OCT. Hence, 52,062 participants were included in the analysis for

177 examining RPE and photoreceptor layer thickness. This large number of exclusions

178 for retinal layers was because of a later start for OCT imaging in UK Biobank, meaning

179 a smaller number of people were scanned.

180

181 The characteristics of participants with data on self-reported AMD and a sub-group

182 with data on retinal layer are shown in Table 1. Both groups had similar 183 sociodemographic and clinical characteristics. Compared to participants with self184 reported $A M D$, those without self-reported AMD were more likely non-white $(9.1 \%$ vs $1857.0 \% ; p=0.01$ ), younger (56.8 years vs 61.6 years), more likely male (46.0\% vs $40.9 \%)$, 186 more likely to come from a more deprived area (less negative Townsend deprivation index) $(-1.1$ vs -1.4$)$ and more likely to be smokers $(9.7 \%$ vs $7.6 \%)$ (all $p<0.001)$ (Supplementary Table 1). The distribution of ambient air pollution exposure of participants with data on self-reported AMD and a sub-group with retinal layer data are shown in Supplementary Table 2. The mean [SD] of the various retinal layers are as follows: total length of photoreceptor $(142.1 \mu \mathrm{m}[8.2 \mu \mathrm{m}])$, photoreceptor synaptic region $(80.4 \mu \mathrm{m}[6.6 \mu \mathrm{m}])$, photoreceptor inner segment $(23.8 \mu \mathrm{m} \quad[2.0 \mu \mathrm{m}])$, photoreceptor outer segment $(37.9 \mu \mathrm{m}[4.3 \mu \mathrm{m}])$ and RPE $(25.6 \mu \mathrm{m}[7.2 \mu \mathrm{m}])$. Of the 115,954 participants, 1,286 (1.1\%) were diagnosed with AMD. Masked grading of OCT and retinal fundus images from 119 participants (60 with self-reported AMD and 59 without self-reported AMD) showed that $75 \%$ of those with self-reported AMD had 
197 OCT features of AMD while only $12 \%$ of those without self-reported AMD had OCT features of AMD.

200 Participants exposed to higher levels of $\mathrm{PM}_{2.5}$ concentration were $8 \%$ more likely to have self-reported $\operatorname{AMD}(\mathrm{OR} 1.08,95 \% \mathrm{Cl} 1.01$ to $1.16 ; p=0.036$, per IQR increase)

(Table 2). Following Bonferroni correction, higher levels of $\mathrm{PM}_{2.5}$ and $\mathrm{NO}_{x}$ were associated with thinner photoreceptor synaptic region (Table 3). In contrast, per IQR increase in $\mathrm{PM}_{2.5}, \mathrm{PM}_{2.5}$ absorbance and $\mathrm{NO}_{2}$ were associated with a thicker photoreceptor inner segment layer. Exposure to higher levels of PM2.5 absorbance,

$\mathrm{PM}_{10}$ and $\mathrm{NO}_{2}$ were associated with a thicker photoreceptor outer segment layer

(Table 3). Higher concentration of $\mathrm{PM}_{2.5}, \mathrm{PM}_{2.5}$ absorbance, $\mathrm{PM}_{10}$ and $\mathrm{NO}_{2}$ were associated with a thinner RPE layer (Table 4). In addition, we examined the association of smoking status with self-reported AMD. Among participants with selfreported AMD, 510/1,286 (39.7\%) and 101/1,286 (7.9\%) were previous and current smokers, respectively. After adjusting for age, sex, race, Townsend deprivation index, BMI, SER and PM2.5, compared to never smoking, previous and current smokers were not associated with self-reported AMD ( $p>0.05)$. We have additionally adjusted for

214 hypertension in the multivariable models in view of its relationship with $\mathrm{AMD}^{24}$ and air 215 pollution. ${ }^{25}$ The associations of air pollutants with self-reported AMD, photoreceptor sub-layers and RPE thickness did not differ after additional adjustment for hypertension. Sensitivity analysis showed that participants with higher exposure to PM2.5 was marginally associated with visually significant self-reported AMD $(n=167)$ (OR $1.18,95 \%$ Cl 0.98 to $1.41 ; p=0.08$, per IQR increase) compared to participants with either no self-reported AMD or those with non-visually significant self-reported 
222 statistically significant with visually significant self-reported AMD. In the sensitivity analysis, we have also additionally adjusted for smoking pack years and there was a

224 borderline significant association between $\mathrm{PM}_{2.5}$ and self-reported AMD (OR 1.07, $22595 \% \mathrm{Cl} 0.99$ to $1.16 ; \mathrm{p}=0.07$, per IQR increase).

\section{Discussion}

228 In this large study of UK Biobank participants, we have identified novel associations between ambient outdoor air pollutant levels at participants' residential addresses with self-reported AMD, and also with retinal structure (including thickness of photoreceptor and RPE layers on OCT imaging).

233 Our results showed that greater ambient $\mathrm{PM}_{2.5}$ exposure was associated with

234 increased odds of $\mathrm{AMD}$ and corresponding retinal thicknesses (specifically 235 photoreceptor sub-layer and RPE). No such significant associations were observed

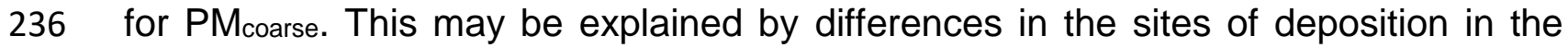
respiratory tract and the sources and chemical composition for these different-sized PM. ${ }^{26}$ PMcoarse are primarily produced from mechanical grinding, windblown dust, and agricultural activities, and mainly deposit in the upper and larger airways. In contrast, $\mathrm{PM}_{2.5}$ particles are mainly from combustion process and are able to reach the smaller 241 airways and alveoli and are transmitted to the blood, ${ }^{27}$ causing a cascade of 242 physiological events associated with morbidity and mortality. ${ }^{5,28}$ The deeper penetration of $\mathrm{PM}_{2.5}$ may account for the stronger associations of $\mathrm{PM}_{2.5}$ with selfreported AMD and structural biomarkers observed in our study. 
$246 \mathrm{NO}_{2}$ is a product of combustion, primarily from traffic- and industrial sources, and one

247 of the most notable ambient air pollutants associated with health effects. ${ }^{29,30}$ Similarly,

$248 \mathrm{NO}_{\mathrm{x}}$ is produced from the reaction of nitrogen and oxygen gases in the air during 249 combustion. ${ }^{31} \mathrm{NO}_{x}$ contributes to the formation of fine particles and ground level 250 ozone. PM2.5 absorbance, a measurement of the blackness of PM2.5 filter - a proxy 251 for elemental or black carbon, is also an indicator of combustion particles. Since the major source of $\mathrm{NO}_{2}, \mathrm{NO}_{x}$ and $\mathrm{PM}_{2.5}$ absorbance is from combustion particles, it may explain the similar associations observed between these air pollutants with the retinal structures. A recent longitudinal population-based study using data from the Taiwan National Health Insurance Program between years 2000-2010 included 39,819 AMD256 free participants, with 1442 participants developing AMD during the 11-year follow up. AMD status was defined via International Classification of Diseases, Ninth Revision, Clinical Modification (ICD-9-CM). Compared to participants in the lowest exposure quartile, those in the highest quartile of $\mathrm{NO}_{2}$ and carbon monoxide $(\mathrm{CO})$ had increased risk of self-reported $\mathrm{AMD}\left(\mathrm{NO}_{2}: \mathrm{HR}=1.91,95 \% \mathrm{Cl} 1.64-2.23, \mathrm{p}<0.001\right.$ and $\mathrm{CO}$ : $\mathrm{HR}=1.84,95 \% \mathrm{Cl} 1.50-2.15, \mathrm{p}<0.001$, respectively). ${ }^{8}$ The difference in findings between ours and the Taiwanese study may be related to the study population, definition and proportion of AMD cases, type and method of estimating the exposure of air pollutants and type of covariates adjusted in the multivariable models. Compared to our study, the Taiwan study included slightly older participants (mean=62 years vs 56 years), had a slightly higher proportion of AMD (3.6\% vs $1.1 \%)$ and estimated a smaller number of air pollutants (two air pollutants including $\mathrm{NO}_{2}$ and $\mathrm{CO}$ vs six air pollutants). In addition, the participant's living area was defined based on the treatment venue for acute upper respiratory tract infection in the Taiwan study. The effect of 
270 pollution on retinal structure associated with AMD were not examined in the Taiwan

271 study.

272

273 Ambient air pollution could plausibly be associated with AMD through oxidative stress

274 or inflammation. Oxidative damage induces many adverse biological effects including

275 lipid, protein, deoxyribonucleic acid (DNA) oxidation, initiation of proinflammatory

276 processes, ${ }^{28}$ and RPE apoptosis. ${ }^{32}$ Atrophic or "dry" AMD, also known as geographic

277 atrophy is by degeneration of RPE cells, followed by loss of photoreceptor cells and choriocapillaris. ${ }^{33}$ Since the RPE is involved in the turnover of photoreceptor outer segments, RPE dysfunction may lead to thickening of photoreceptor outer segments.

Our results showed that $\mathrm{PM}_{2.5}$ and $\mathrm{NO}_{\mathrm{x}}$ were associated with a thinner photoreceptor synaptic region. This is in agreement with a reduction in the number of photoreceptor synaptic terminals overlying drusen in $\mathrm{AMD}^{34}$ In contrast, $\mathrm{PM}_{2.5}, \mathrm{PM}_{2.5}$ absorbance and $\mathrm{NO}_{2}$ were associated with thicker photoreceptor inner segment, while $\mathrm{PM}_{2.5}$ absorbance, $\mathrm{NO}_{2}$ and $\mathrm{PM}_{10}$ were associated with thicker photoreceptor outer segment. As mitochondria are prominent in photoreceptor inner segments, oxidative stress may induce mitochondrial swelling, ${ }^{35}$ leading to a slight thickening in the photoreceptor inner segment. Abnormalities in the photoreceptor inner and outer segments have also been reported in retinal toxicity associated with hydroxychloroquine. ${ }^{36}$ Our study did not show an association between air pollution and average total photoreceptor layer thickness, which may be explained by thinning of the synaptic region cancelling out the thickening of the inner/outer segments. In a study by Schuman et al., although the authors reported decreased photoreceptor thickness over drusen, there was a lack of 
294 widespread photoreceptor loss. ${ }^{37}$ Hence, it is possible that there was focal loss of the photoreceptor thickness in our study but an overall loss of photoreceptor layer was not observed.

Cigarette smoking may also contribute to particulate matter air pollution. ${ }^{38}$ Because of the previously recorded, very strong link between $\mathrm{AMD}$ and smoking, ${ }^{39}$ and the plausible link between smoking and particulate air pollution, we examined the association between smoking status of participants with self-reported AMD and did not observe a significant association. This suggests that the relationship between $\mathrm{PM}_{2.5}$ and self-reported AMD is not mediated by cigarette smoke. The prevalence of late AMD standardized to the UK population aged 50 years or more and 65 years or more was $2.4 \%$ and $4.8 \%$, respectively. Prevalence of geographic atrophy was $1.3 \%$ and $2.5 \%$ for the respective age groups. ${ }^{40}$ The European Eye Epidemiology (E3) Consortium performed a meta-analysis and showed that overall prevalence was $13.2 \%$ for early $\mathrm{AMD}$ and $3.0 \%$ for late $\mathrm{AMD}$ for people aged 70 years or older. ${ }^{41}$ Compared to the E3 Consortium, participants in UK Biobank are slightly younger and include a healthier population than the rest of UK population. ${ }^{42}$ The self-reported AMD cases in our study may represent AMD in the early stages. We compared the visual acuity between participants with and without self-reported AMD. Among those with self-reported AMD, there was a higher proportion of participants with visual impairment

314 (VA worse than LogMAR 0.3) compared to those without visual impairment (1.8\% vs $1.0 \% ; p<0.001)$. The proportion of self-reported AMD (1.1\%) in our study may have

316 been underestimated and it is likely that the risk estimates may have been underestimated. 
319 In addition to the increased risk of AMD associated with higher exposure to air pollution 320 in the Taiwanese study, other studies in the UK Biobank ${ }^{43}$ and China ${ }^{7}$ have reported 321 increased odds of glaucoma with higher exposure to PM2.5. In the UK Biobank study 322 of 111,370 participants, greater exposure to $\mathrm{PM}_{2.5}$ was associated with both selfreported glaucoma and retinal structures associated with the disease. ${ }^{43}$ Wang et al. reported that higher average levels of $\mathrm{PM}_{2.5}$ was associated with higher burden of glaucoma disability, using national level data. ${ }^{7}$ The New England-based Normative Aging Study showed an association between black carbon exposure with IOP that was

327 greater in individuals with a high oxidative stress allelic score. ${ }^{44}$ Taken together, our results support published findings of increased risk of eye diseases or association with retinal structures in participants with higher exposure to ambient air pollution. As certain groups of individuals including people with diabetes mellitus ${ }^{45}$ or 331 hypertension ${ }^{24}$ may have increased risk of AMD, it will be useful to explore if these groups of individuals are at greater risk of eye disease when exposed to air pollution in future analysis.

335 Strength of this study include its large sample size and the highly accurate and reproducible measurements of the OCT retinal thickness. Limitations of the study

337 include the UK Biobank is a volunteer cohort, and participants are likely healthier than 338 the general population. Outdoor air pollution was estimated using the participants' 339 home address and do not explain all variation in indoor concentrations. As most 340 individuals spend a large amount of time indoors, individual exposure to all forms of air pollution may differ from that indicated by the ambient outdoor figures. This is most 
342 likely to be non-differential between cases and controls and will therefore skew the 343 associations towards the null. Another limitation of this analysis was the use of self-

344 report as the sole determinant of AMD status rather than incorporating a qualitative 345 analysis of the colour fundus photographs and SD-OCT imaging, though we did carry 346 out masked grading of retinal imaging in a proportion of participants. This may result 347 in non-differential misclassification bias and most likely bias the estimates towards the 348 null. Although we applied strict automated quality control criteria including a manual 349 check of SD-OCT scans with high and low outlying layer thickness, ${ }^{17}$ it was not 350 practical to manually check all OCT scans for segmentation accuracy. Selection bias 351 may exist: out of the 115,954 participants with data on self-reported AMD, 52,602 participants had measurements on outer retinal layers. However, the baseline characteristics (Table 1) across the two AMD-associated outcome groups appear to be similar. The cross-sectional design of our study limits the ability to determine the causality between ambient air pollution and AMD-associated outcomes. Further research is needed to probe the relationship between prior air pollution exposure and risk of incident disease.

In this large study of an older middle-aged UK population, higher $\mathrm{PM}_{2.5}$ exposure was associated with a higher risk of self-reported AMD, while all pollutants except PMcoarse were associated with changes in retinal structure (in either photoreceptor sublayer and/or RPE layer thickness). Overall, our findings suggest that ambient air pollution, especially fine PM or those of combustion-related particles, may affect AMD risk. It is possible that the structural features observed may be unrelated to AMD, but associated with pollution induced retinal toxicity. However, the direction of the 
367 thicknesses indicate higher exposure to air pollution may make the cells more 368 vulnerable and increase the risk of AMD. Our findings add to the growing evidence of 369 the damaging effects of ambient air pollution, even in the setting of relative low 370 exposure of ambient air pollution. As UK Biobank is a very large prospective cohort, 371 we anticipate being able to explore the effect of particulate matter on future risk of 372 AMD. Further studies examining both outdoor and indoor ambient air pollution 373 estimates on AMD and outer retinal structures may help to substantiate our findings 374 and understand the implications for retinal disease associated with ageing. If our 375 findings are replicated, this would support the view that air pollution is an important 376 modifiable risk factor for AMD. 
Table 1. Demographic, systemic and ocular characteristics of participants with availability of data on self-reported AMD and retinal layers.

\begin{tabular}{|c|c|c|}
\hline & $\begin{array}{c}\text { Participants with data on } \\
\text { self-reported AMD } \\
(\mathrm{N}=115,954)\end{array}$ & $\begin{array}{l}\text { Participants with data on } \\
\text { retinal layers }(\mathrm{N}=52,602)\end{array}$ \\
\hline \multicolumn{3}{|l|}{ Sociodemographic factors } \\
\hline Age & $56.8(8.0)$ & $56.4(8.1)$ \\
\hline \multicolumn{3}{|l|}{ Sex } \\
\hline Men & $53,218(46 \%)$ & $24,753(47 \%)$ \\
\hline Women & $62,736(54 \%)$ & $27,849(53 \%)$ \\
\hline \multicolumn{3}{|l|}{ Race } \\
\hline White & $105,465(91 \%)$ & $48,475(92 \%)$ \\
\hline Non-white & $10,489(9 \%)$ & $4,127(8 \%)$ \\
\hline Townsend deprivation index & $-1.1(3.0)$ & $-1.2(2.9)$ \\
\hline \multicolumn{3}{|l|}{ Clinical factors } \\
\hline Body mass index $\left(\mathrm{kg} / \mathrm{m}^{2}\right)$ & $27.3(4.5)$ & $27.2(4.4)$ \\
\hline \multicolumn{3}{|l|}{ Smoking status } \\
\hline Never & $64,554(56 \%)$ & $29,238(56 \%)$ \\
\hline Previous & $40,224(35 \%)$ & $18,421(35 \%)$ \\
\hline Current & $11,176(10 \%)$ & $4,943(9 \%)$ \\
\hline Spherical equivalent (diopters) & $-0.1(2.1)$ & $0.0(2.0)$ \\
\hline
\end{tabular}

Numbers are mean (SD) or no. (\%), unless otherwise stated.

$\mathrm{AMD}=$ Age-related macular degeneration, $\mathrm{PM}_{2.5}=$ Particular matter (aerodynamic diameter of less than $2.5 \mu \mathrm{m}$ ), $\mathrm{PM}_{2.5}$ absorbance $=$ Particulate matter (a measurement of the blackness of $\mathrm{PM}_{2.5}$ filter - a proxy for elemental or black carbon), $\mathrm{PM}_{\text {coarse }}=$ Particulate matter (aerodynamic diameter between 2.5 and $10 \mu \mathrm{m}, \mathrm{PM}_{10}=$ Particulate matter (aerodynamic diameter of less than $10 \mu \mathrm{m}), \mathrm{NO} 2=$ Nitrogen dioxide, $\mathrm{NO} x=$ Nitrogen oxide 
Table 2: Association of ambient air pollution with self-reported age-relation macular degeneration (AMD)

\begin{tabular}{lccc}
\hline & \multicolumn{3}{c}{ Multivariate regression } \\
\cline { 2 - 4 } & OR & $(95 \% \mathrm{Cl})$ & $P$-value \\
\hline $\begin{array}{c}\text { Air pollution factors } \\
\mathrm{PM}_{2.5}\left(\mu \mathrm{g} / \mathrm{m}^{3}\right)\end{array}$ & 1.08 & $(1.01,1.16)$ & $\mathbf{0 . 0 3 6}$ \\
$\mathrm{PM}_{2.5}$ absorbance & & & \\
$\left(\mu \mathrm{g} / \mathrm{m}^{3}\right)$ & 1.00 & $(0.93,1.07)$ & 0.95 \\
$\mathrm{PM}_{2.5-10}\left(\mu \mathrm{g} / \mathrm{m}^{3}\right)$ & 1.01 & $(0.96,1.07)$ & 0.58 \\
$\mathrm{PM}_{10}\left(\mu \mathrm{g} / \mathrm{m}^{3}\right)$ & 0.94 & $(0.86,1.02)$ & 0.11 \\
$\mathrm{NO}_{2}\left(\mu \mathrm{g} / \mathrm{m}^{3}\right)$ & 0.99 & $(0.91,1.08)$ & 0.80 \\
$\mathrm{NOX}(\mu \mathrm{g} / \mathrm{m} 3)$ & 1.03 & $(0.97,1.09)$ & 0.34 \\
\hline
\end{tabular}

The odds ratio represents per IQR increase in exposure variable.

Values are adjusted for age, sex, race, Townsend deprivation index, body mass index, smoking status and spherical equivalent refraction 
Table 3: Association of ambient air pollution with thickness of the photoreceptor sub-layers

Multivariate regression

\begin{tabular}{|c|c|c|c|c|c|c|c|c|c|c|c|}
\hline \multicolumn{3}{|c|}{ Total photoreceptor } & \multicolumn{3}{|c|}{ Photoreceptor synaptic region } & \multicolumn{3}{|c|}{ Photoreceptor inner segment } & \multicolumn{3}{|c|}{ Photoreceptor outer segment } \\
\hline$\beta$ & $(95 \% \mathrm{Cl})$ & P-value & $\beta$ & $(95 \% \mathrm{Cl})$ & P-value & $\beta$ & $(95 \% \mathrm{Cl})$ & P-value & $\beta$ & $(95 \% \mathrm{Cl})$ & P-value \\
\hline
\end{tabular}

\begin{tabular}{|c|c|c|c|c|c|c|c|c|c|c|c|c|}
\hline \multicolumn{13}{|l|}{ Air pollution factors } \\
\hline $\mathrm{PM}_{2.5}\left(\mu \mathrm{g} / \mathrm{m}^{3}\right)$ & -0.07 & $(-0.16,0.02)$ & 0.15 & -0.16 & $(-0.23,-0.09)$ & $2.0 \times 10^{-5}$ & 0.04 & $(0.02,0.06)$ & 0.001 & 0.05 & $(0.003,0.10)$ & 0.04 \\
\hline $\mathrm{PM}_{2.5}$ absorbance $\left(\mu \mathrm{g} / \mathrm{m}^{3}\right)$ & 0.06 & $(-0.03,0.14)$ & 0.22 & -0.10 & $(-0.17,-0.03)$ & 0.004 & 0.04 & $(0.02,0.06)$ & $2.0 \times 10^{-4}$ & 0.12 & $(0.07,0.17)$ & $8.7 \times 10^{-7}$ \\
\hline $\mathrm{PM}_{\text {coarse }}\left(\mu \mathrm{g} / \mathrm{m}^{3}\right)$ & -0.04 & $(-0.11,0.02)$ & 0.18 & -0.03 & $(-0.08,0.02)$ & 0.21 & -0.008 & $(-0.02,0.007)$ & 0.32 & -0.003 & $(-0.04,0.03)$ & 0.85 \\
\hline $\mathrm{PM}_{10}\left(\mu \mathrm{g} / \mathrm{m}^{3}\right)$ & 0.04 & $(-0.06,0.14)$ & 0.47 & -0.05 & $(-0.13,0.03)$ & 0.24 & -0.002 & $(-0.01,0.007)$ & 0.63 & 0.09 & $(0.04,0.15)$ & 0.001 \\
\hline $\mathrm{NO}_{2}\left(\mu \mathrm{g} / \mathrm{m}^{3}\right)$ & 0.15 & $(0.04,0.26)$ & 0.004 & -0.06 & $(-0.14,0.03)$ & 0.19 & 0.04 & $(0.02,0.07)$ & 0.001 & 0.17 & $(0.11,0.22)$ & $1.1 \times 10^{-8}$ \\
\hline $\mathrm{NO} \times\left(\mu \mathrm{g} / \mathrm{m}^{3}\right)$ & -0.02 & $(-0.09,0.06)$ & 0.63 & -0.10 & $(-0.16,-0.04)$ & 0.001 & 0.03 & $(0.008,0.04)$ & 0.004 & 0.05 & $(0.01,0.09)$ & 0.009 \\
\hline
\end{tabular}

The beta coefficients represent per IQR increase in exposure variable.
Values are adjusted for age, sex, race, Townsend deprivation index, body mass index, smoking status and refractive error.

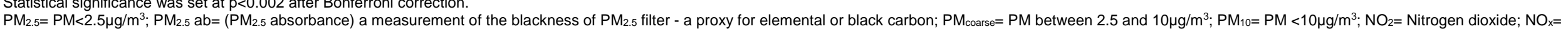
Nitrogen oxide

379 
Table 4: Association of ambient air pollution with thickness of the retinal pigment epithelium layer

\section{Multivariate regression}

RPE

\begin{tabular}{|c|c|c|c|}
\hline & $\beta$ & $(95 \% \mathrm{Cl})$ & P-value \\
\hline \multicolumn{4}{|l|}{ Air pollution factors } \\
\hline $\mathrm{PM}_{2.5}\left(\mu \mathrm{g} / \mathrm{m}^{3}\right)$ & -0.13 & $(-0.21,-0.05)$ & 0.002 \\
\hline PM2.5 absorbance $\left(\mu \mathrm{g} / \mathrm{m}^{3}\right)$ & -0.09 & $(-0.17,-0.008)$ & 0.03 \\
\hline PMcoarse $\left(\mu \mathrm{g} / \mathrm{m}^{3}\right)$ & -0.02 & $(-0.08,0.04)$ & 0.50 \\
\hline $\mathrm{PM}_{10}\left(\mu \mathrm{g} / \mathrm{m}^{3}\right)$ & -0.12 & $(-0.21,-0.02)$ & 0.01 \\
\hline $\mathrm{NO}_{2}\left(\mu \mathrm{g} / \mathrm{m}^{3}\right)$ & -0.12 & $(-0.21,-0.02)$ & 0.01 \\
\hline $\mathrm{NO} \times\left(\mu \mathrm{g} / \mathrm{m}^{3}\right)$ & -0.05 & $(-0.12,0.02)$ & 0.17 \\
\hline
\end{tabular}

The beta coefficients represent per IQR increase in exposure variable.

Values are adjusted for age, sex, race, Townsend deprivation index, body mass index, smoking status and refractive error. Statistical significance was set at $p<0.05$.

$\mathrm{RPE}=$ Retinal pigment epithelium; $\mathrm{PM}_{2.5}=$ Particulate matter less than $2.5 \mu \mathrm{m}$ in aerodynamic diameter; $\mathrm{PM} 2.5 \mathrm{ab}=\left(\mathrm{PM}_{2.5}\right.$ absorbance) a measurement of the blackness of $\mathrm{PM}_{2.5}$ filter - a proxy for elemental or black carbon; PMcoarse= Particulate matter between $2.5 \mu \mathrm{m}$ to $10 \mu \mathrm{m}$ in aerodynamic diameter; $\mathrm{PM}_{10}=$ Particulate matter less than $10 \mu \mathrm{m}$ in aerodynamic diameter; $\mathrm{NO}_{2}=$

Nitrogen dioxide; $\mathrm{NO}=$ Nitrogen oxide 


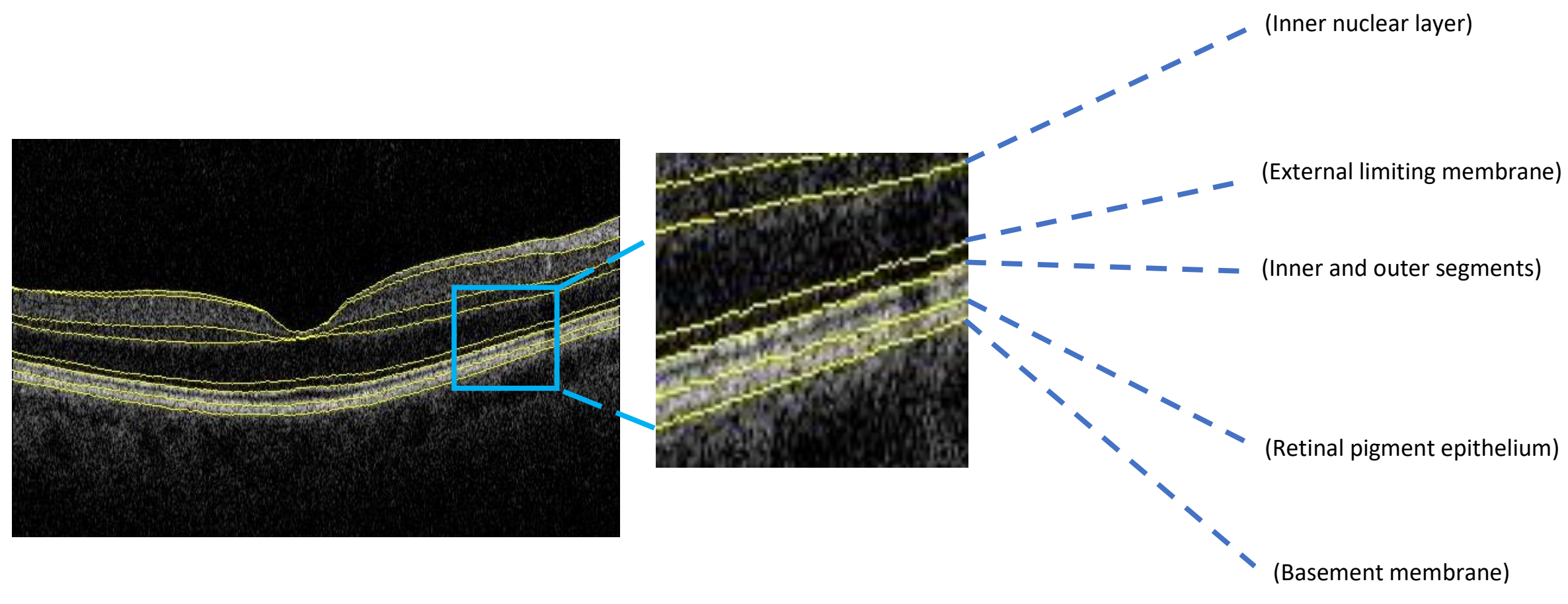

Supplementary Figure 1. Spectral-domain optical coherence tomography images with schematic showing representative of total photoreceptor (Inner nuclear layer-Retinal pigment epithelium); photoreceptor synaptic region (Inner nuclear layer- External limiting membrane); photoreceptor inner segment (External limiting membrane-Inner and outer segments); photoreceptor outer segment (Inner and outer segments-Retinal pigment epithelium) and retinal pigment epithelium (Retinal pigment epithelium-Basement membrane). 
Supplementary Table 1. Comparison of characteristics between participants with self-reported AMD and without self-reported AMD

\begin{tabular}{|c|c|c|c|}
\hline & $\begin{array}{c}\text { No self-reported AMD } \\
(\mathrm{N}=114,668)\end{array}$ & $\begin{array}{c}\text { Self-reported AMD } \\
(\mathrm{N}=1,286)\end{array}$ & P-value \\
\hline \multicolumn{4}{|l|}{ Sociodemographic factors } \\
\hline Age & $56.8(8.1)$ & $61.6(5.9)$ & $<0.001$ \\
\hline \multicolumn{4}{|l|}{ Sex } \\
\hline Men & $52,692(46.0 \%)$ & $526(40.9 \%)$ & \\
\hline Women & $61,976(54.0 \%)$ & $760(59.1 \%)$ & $<0.001$ \\
\hline \multicolumn{4}{|l|}{ Race } \\
\hline White & $104,269(90.9 \%)$ & $1,196(93.0 \%)$ & \\
\hline Non-white & $10,399(9.1 \%)$ & $90(7.0 \%)$ & 0.01 \\
\hline Townsend deprivation index & $-1.1(3.0)$ & $-1.5(2.9)$ & $<0.001$ \\
\hline \multicolumn{4}{|l|}{ Clinical factors } \\
\hline Body mass index $\left(\mathrm{kg} / \mathrm{m}^{2}\right)$ & $27.2(4.5)$ & $27.4(4.3)$ & 0.18 \\
\hline \multicolumn{4}{|l|}{ Smoking status } \\
\hline Never & $63,879(55.7 \%)$ & $675(52.5 \%)$ & \\
\hline Previous & $39,714(34.6 \%)$ & $510(39.7 \%)$ & \\
\hline Current & $11,075(9.7 \%)$ & $101(7.8 \%)$ & $<0.001$ \\
\hline Spherical equivalent (diopters) & $-0.08(2.1)$ & $-0.03(2.3)$ & 0.40 \\
\hline
\end{tabular}


Supplementary Table 2. Distribution of $\mathrm{PM}_{2.5}, \mathrm{PM}_{\text {coarse, }} \mathrm{PM}_{10}, \mathrm{NO}_{2}$ and $\mathrm{NOx}$ of participants with availability of data on self-reported AMD and retinal layers

\begin{tabular}{|c|c|c|c|c|}
\hline & \multicolumn{2}{|c|}{$\begin{array}{c}\text { Self-reported AMD } \\
(\mathrm{N}=115,954)\end{array}$} & \multicolumn{2}{|c|}{$\begin{array}{c}\text { Retinal layers } \\
(\mathrm{N}=52,602)\end{array}$} \\
\hline & Median (IQR) & Range & Median (IQR) & Range \\
\hline $\mathrm{PM}_{2.5}\left(\mu \mathrm{g} / \mathrm{m}^{3}\right)$ & $9.91(1.07)$ & $(8.17,19.69)$ & $9.88(1.12)$ & $(8.17,19.69)$ \\
\hline PM2.5 absorbance $\left(\mu \mathrm{g} / \mathrm{m}^{3}\right)$ & $1.22(0.33)$ & $(0.83,4.05)$ & $1.22(0.33)$ & $(0.83,3.71)$ \\
\hline PMcoarse $\left(\mu \mathrm{g} / \mathrm{m}^{3}\right)$ & $6.19(0.75)$ & $(5.57,12.82)$ & $6.21(0.77)$ & $(5.57,11.30)$ \\
\hline $\mathrm{PM}_{10}\left(\mu \mathrm{g} / \mathrm{m}^{3}\right)$ & $19.37(2.67)$ & $(13.04,29.67)$ & $19.33(2.77)$ & $(13.38,29.30)$ \\
\hline Nitrogen dioxide $\left(\mathrm{NO}_{2}\right)\left(\mu \mathrm{g} / \mathrm{m}^{3}\right)$ & $31.75(12.08)$ & $(9.44,102.75)$ & $31.25(12.63)$ & $(9.44,86.65)$ \\
\hline Nitrogen oxide (NOx) $\left(\mu \mathrm{g} / \mathrm{m}^{3}\right)$ & $43.66(14.38)$ & $(19.74,263.96)$ & $43.17(14.97)$ & $\begin{array}{l}(19.74 \\
263.96)\end{array}$ \\
\hline
\end{tabular}




\section{Acknowledgements \& Funding}

\section{Funding:}

The UK Biobank Eye and Vision Consortium is supported by grants from Moorfields Eye Charity, The NIHR Biomedical Research Centre at Moorfields Eye Hospital NHS Foundation Trust and UCL Institute of Ophthalmology, the Alcon Research Institute and the International Glaucoma Association (UK).

No funders had a direct role in the collection, management, analysis, or interpretation of the data; preparation, review, or approval of the manuscript; nor in the decision to submit the manuscript for publication.

\section{Acknowledgements}

SYLC, PTK, PJF, and PJP received salary support from the NIHR BRC at Moorfields Eye Hospital.

PTK is supported in part by the Helen Hamlyn Trust. PJF received support from the Richard Desmond Charitable Trust, via Fight for Sight, London.

APK is supported by a Moorfields Eye Charity Career Development Fellowship. The authors acknowledge a proportion of our financial support from the UK Department of Health through an award made by the National Institute for Health Research to Moorfields Eye Hospital NHS Foundation Trust and UCL Institute of Ophthalmology for a Biomedical Research Centre for Ophthalmology.

This research used data from the UK Biobank Resource, under data access request number 2112.

\section{Conflict of Interest:}

CR reports employment by Topcon Healthcare Solutions, Inc. outside the submitted work. PJF reports personal fees from Allergan, Carl Zeiss, Google/DeepMind and Santen, a grant from Alcon, outside the submitted work; PJP reports grants from Topcon Inc, outside the submitted work.

Ethical approval: The North West Multi-center Research Ethics Committee approved the study (reference no., 06/MRE08/65), in accordance with the tenets of the Declaration of Helsinki. Detailed information about the study is available at the UK Biobank web site (www.ukbiobank.ac.uk)

\section{Authors' Contributions:}

SYLC had full access to all of the data in the study and takes responsibility for the integrity of the data and the accuracy of the data analysis.

PJF and PJP led conception and design of the study.

SYLC,PJF and PJP contributed to the data analyses, data interpretation and wrote the draft of the manuscript.

All authors reviewed the results, read and critically revised the manuscript. All authors approved the final manuscript.

The corresponding author attests that all listed authors meet authorship criteria and that no others meeting the criteria have been omitted. 
1. Mitchell P, Liew G, Gopinath B, Wong TY. Age-related macular degeneration. The Lancet 2018; 392(10153): 1147-59.

2. McLeod DS, Grebe R, Bhutto I, Merges C, Baba T, Lutty GA. Relationship between RPE and choriocapillaris in age-related macular degeneration. Invest Ophthalmol Vis Sci 2009; 50(10): 4982-91.

3. Wong WL, Su X, Li X, et al. Global prevalence of age-related macular degeneration and disease burden projection for 2020 and 2040: a systematic review and meta-analysis. The Lancet Global health 2014; 2(2): e106-16.

4. Seddon JM, Francis PJ, George S, Schultz DW, Rosner B, Klein ML. Association of CFH $\mathrm{Y} 402 \mathrm{H}$ and LOC387715 A69S with progression of age-related macular degeneration. Jama 2007; 297(16): 1793-800.

5. Cohen AJ, Brauer M, Burnett R, et al. Estimates and 25-year trends of the global burden of disease attributable to ambient air pollution: an analysis of data from the Global Burden of Diseases Study 2015. Lancet (London, England) 2017; 389(10082): 1907-18.

6. Lelieveld J, Evans JS, Fnais M, Giannadaki D, Pozzer A. The contribution of outdoor air pollution sources to premature mortality on a global scale. Nature 2015; 525(7569): 367-71.

7. Wang W, He M, Li Z, Huang W. Epidemiological variations and trends in health burden of glaucoma worldwide. Acta ophthalmologica 2019; 97(3): e349-e55.

8. Chang K-H, Hsu P-Y, Lin C-J, Lin C-L, Juo S-HH, Liang C-L. Traffic-related air pollutants increase the risk for age-related macular degeneration. Journal of Investigative Medicine 2019: jim-2019-001007.

9. Lodovici M, Bigagli E. Oxidative stress and air pollution exposure. J Toxicol 2011; 2011: 487074.

10. Jarrett SG, Boulton ME. Consequences of oxidative stress in age-related macular degeneration. Molecular aspects of medicine 2012; 33(4): 399-417.

11. Puliafito CA, Hee MR, Lin CP, et al. Imaging of macular diseases with optical coherence tomography. Ophthalmology 1995; 102(2): 217-29.

12. Chua SYL, Thomas D, Allen N, et al. Cohort profile: design and methods in the eye and vision consortium of UK Biobank. BMJ open 2019; 9(2): e025077.

13. Cumberland PM, Rahi JS, Eye UKB, Vision C. Visual Function, Social Position, and Health and Life Chances: The UK Biobank Study. JAMA Ophthalmol 2016; 134(9): 959-66.

14. Cumberland PM, Bao Y, Hysi PG, et al. Frequency and Distribution of Refractive Error in Adult Life: Methodology and Findings of the UK Biobank Study. PLoS One 2015; 10(10): e0139780.

15. Yang $Q$, Reisman CA, Wang Z, et al. Automated layer segmentation of macular OCT images using dual-scale gradient information. Optics express 2010; 18(20): 21293-307.

16. Ko F, Foster PJ, Strouthidis NG, et al. Associations with Retinal Pigment Epithelium Thickness Measures in a Large Cohort: Results from the UK Biobank. Ophthalmology 2017; 124(1): 105-17.

17. Patel PJ, Foster PJ, Grossi CM, et al. Spectral-Domain Optical Coherence Tomography Imaging in 67321 Adults: Associations with Macular Thickness in the UK Biobank Study. Ophthalmology 2016; 123(4): 829-40. 
18. Khawaja AP, Chua S, Hysi PG, et al. Comparison of Associations with Different Macular Inner Retinal Thickness Parameters in a Large Cohort: The UK Biobank.

Ophthalmology 2019.

19. Ferris FL, 3rd, Wilkinson CP, Bird A, et al. Clinical classification of age-related macular degeneration. Ophthalmology 2013; 120(4): 844-51.

20. Aung N, Sanghvi Mihir M, Zemrak F, et al. Association Between Ambient Air Pollution and Cardiac Morpho-Functional Phenotypes. Circulation 2018; 138(20): 2175-86.

21. Eeftens M, Beelen R, de Hoogh K, et al. Development of Land Use Regression models for $\mathrm{PM}(2.5), \mathrm{PM}(2.5)$ absorbance, $\mathrm{PM}(10)$ and PM(coarse) in 20 European study areas; results of the ESCAPE project. Environmental science \& technology 2012; 46(20): 11195-205. 22. Cruz-Herranz A, Balk $\amalg$, Oberwahrenbrock T, et al. The APOSTEL recommendations for reporting quantitative optical coherence tomography studies. Neurology 2016; 86(24): 2303-9.

23. Vujosevic S, Midena E. Retinal layers changes in human preclinical and early clinical diabetic retinopathy support early retinal neuronal and Muller cells alterations. Journal of diabetes research 2013; 2013: 905058.

24. Hyman L, Schachat AP, He Q, Leske MC. Hypertension, cardiovascular disease, and age-related macular degeneration. Age-Related Macular Degeneration Risk Factors Study Group. Archives of ophthalmology (Chicago, III : 1960) 2000; 118(3): 351-8.

25. Ibald-Mulli A, Stieber J, Wichmann HE, Koenig W, Peters A. Effects of air pollution on blood pressure: a population-based approach. Am J Public Health 2001; 91(4): 571-7.

26. Wilson WE, Suh $\mathrm{HH}$. Fine particles and coarse particles: concentration relationships relevant to epidemiologic studies. Journal of the Air \& Waste Management Association (1995) 1997; 47(12): 1238-49.

27. Brown DM, Wilson MR, MacNee W, Stone V, Donaldson K. Size-dependent proinflammatory effects of ultrafine polystyrene particles: a role for surface area and oxidative stress in the enhanced activity of ultrafines. Toxicology and applied pharmacology 2001; 175(3): 191-9.

28. Brook RD, Rajagopalan S, Pope CA, 3rd, et al. Particulate matter air pollution and cardiovascular disease: An update to the scientific statement from the American Heart Association. Circulation 2010; 121(21): 2331-78.

29. Gaffin JM, Hauptman M, Petty CR, et al. Nitrogen dioxide exposure in school classrooms of inner-city children with asthma. Journal of Allergy and Clinical Immunology 2018; 141(6): 2249-55.e2.

30. World Health Organization. Air quality guidelines-global update 2005. http://www.who.int/phe/health topics/outdoorair/outdoorair_aqg/en/ (accessed 20 Feburary 2019).

31. Icopal. Nitrogen Oxide (NOx) Pollution. http://www.icopal-noxite.co.uk/noxproblem/nox-pollution.aspx (accessed 15 April 2020).

32. Jiang S, Moriarty-Craige SE, Orr M, Cai J, Sternberg P, Jr, Jones DP. Oxidant-Induced Apoptosis in Human Retinal Pigment Epithelial Cells: Dependence on Extracellular Redox State. Investigative Ophthalmology \& Visual Science 2005; 46(3): 1054-61.

33. Sarks JP, Sarks SH, Killingsworth MC. Evolution of geographic atrophy of the retinal pigment epithelium. Eye (Lond) 1988; 2 ( Pt 5): 552-77.

34. Johnson PT, Brown MN, Pulliam BC, Anderson DH, Johnson LV. Synaptic Pathology, Altered Gene Expression, and Degeneration in Photoreceptors Impacted by Drusen. Investigative Ophthalmology \& Visual Science 2005; 46(12): 4788-95. 
35. Wilson JD, Bigelow CE, Calkins DJ, Foster TH. Light scattering from intact cells reports oxidative-stress-induced mitochondrial swelling. Biophysical journal 2005; 88(4): 2929-38.

36. Rodriguez-Padilla JA, Hedges TR, 3rd, Monson B, et al. High-speed ultra-highresolution optical coherence tomography findings in hydroxychloroquine retinopathy. Archives of ophthalmology (Chicago, III : 1960) 2007; 125(6): 775-80.

37. Schuman SG, Koreishi AF, Farsiu S, Jung SH, Izatt JA, Toth CA. Photoreceptor layer thinning over drusen in eyes with age-related macular degeneration imaged in vivo with spectral-domain optical coherence tomography. Ophthalmology 2009; 116(3): 488-96.e2. 38. Repace JL, Lowrey AH. Indoor air pollution, tobacco smoke, and public health. Science (New York, NY) 1980; 208(4443): 464-72.

39. Tomany SC, Wang JJ, van Leeuwen R, et al. Risk factors for incident age-related macular degeneration: Pooled findings from 3 continents. Ophthalmology 2004; 111(7): 1280-7.

40. Owen CG, Jarrar Z, Wormald R, Cook DG, Fletcher AE, Rudnicka AR. The estimated prevalence and incidence of late stage age related macular degeneration in the UK. $\mathrm{Br} J$ Ophthalmol 2012; 96(5): 752-6.

41. Colijn JM, Buitendijk GHS, Prokofyeva E, et al. Prevalence of Age-Related Macular Degeneration in Europe: The Past and the Future. Ophthalmology 2017; 124(12): 1753-63. 42. Fry A, Littlejohns TJ, Sudlow C, et al. Comparison of Sociodemographic and HealthRelated Characteristics of UK Biobank Participants With Those of the General Population. Am J Epidemiol 2017; 186(9): 1026-34.

43. Chua SYL, Khawaja AP, Morgan J, et al. The Relationship Between Ambient Atmospheric Fine Particulate Matter (PM2.5) and Glaucoma in a Large Community Cohort. Investigative Ophthalmology \& Visual Science 2019; 60(14): 4915-23.

44. Nwanaji-Enwerem JC, Wang W, Nwanaji-Enwerem O, et al. Association of Long-term Ambient Black Carbon Exposure and Oxidative Stress Allelic Variants With Intraocular Pressure in Older Men. JAMA Ophthalmol 2019; 137(2): 129-37.

45. Choi JK, Lym YL, Moon JW, Shin HJ, Cho B. Diabetes Mellitus and Early Age-related Macular Degeneration. Archives of Ophthalmology 2011; 129(2): 196-9. 